\title{
Perception of Teachers towards Inclusive Education (PTIE): An Investigation on Scale Construct and Item Calibration
}

\author{
Ka-Lam Sam, Fuk-Chuen Ho, and Sze-Ching Lam
}

\begin{abstract}
Perception of teacher has been supported by recent research which influences their behavior towards acceptance of students with special learning needs. This study examines the psychometric properties of a newly constructed measure on teacher perception towards inclusive education. The study comprised 355 teachers (mostly females; majority age group: 26 to 45 ) from three progressive teacher training courses (basic, advanced, and thematic), which cater to different educational needs. The participants were required to complete the questionnaire on their perception towards educational inclusion. Data were analyzed using both classic test theory (CTT) and item response theory (IRT). Three domains (attitude, concern, and commitment) of perception were identified and tested in the context of Hong Kong. The analysis showed these domains had strong construct validity (GFI=.986; CFI=.941; RMSEA=.0578), internal consistency (Cronbach's alpha=.529-.761), and good fit to the Rasch model among items (Infit/outfit=.80-1.27). The current findings support the view that administration of the recent scale provided better understanding of teachers' perception on inclusive setting, and improved guidance for better program development on teacher training.
\end{abstract}

Index Terms - Teacher perception, inclusive education, PTIE, item calibration, scale validation.

\section{INTRODUCTION}

The philosophy of educational values of equity and social justice makes the entitlement of all children to quality education, regardless of differences, an important notion for the implementation of inclusive education [1], [2]. However, several teachers have reservations for the inclusion of students with special educational needs in ordinary classrooms. The reservation could have been the result of the worries of teachers concerning their insufficient professional preparation to deal with students with special educational needs. Prior studies proved that involvement in strategic professional development helps teachers increase their understanding of learning barriers and changes their negative perspectives on students with special educational needs [3]. Professional development programs help teachers develop attitudes, strategies, and capacities to work with others, which in turn allow them to facilitate students regardless of their disabilities in the inclusion setting [4], [5]. According to Burrello and Wright (1993), targeted professional

Manuscript received May 14, 2015; revised July 10, 2015. This study was supported by a grant EDB(SES2)/P-SUP/41(14) from the Education Bureau, Government of the Hong Kong Special Administrative Region.

K. L. Sam is with the Faculty of Social Sciences, Hong Kong Baptist University, Hong Kong (e-mail: samsam@life.hkbu.edu.hk).

F. C. Ho and S. C. Lam are with the Department of Special Education and Counselling, Faculty of Education and Human Development, The Hong Kong Institute of Education, Hong Kong (e-mail: fcho@ied.edu.hk, ciclam@ied.edu.hk). development activities focused around inclusion increases staff efficacy and attitudes in the areas of team collaboration, cooperative learning, joint ownership, student integration, effective teaching practices, and development of teaching skills in adapting and modifying the curriculum to meet the needs of all students [6]. However, limited studies have been conducted to prove the effectiveness of professional development programs on the influential function on the attitudes, concern, and commitment of teachers, especially in the Chinese schools. One of the major reasons for the lack of studies is the limited number of psychometric tools for evaluating the latent indicators.

Teacher attitudes generally have a significant impact on the student educational outcomes [1], [2], [7], [8]. In the climate of inclusion, teacher attitudes towards children and young people with special educational needs are highly relevant. Based on Western studies, several factors influence teacher attitudes towards inclusion, including the nature and severity of the special needs. Specifically, teachers were more accepting of children with physical disabilities and were "cautiously accepting" children with learning difficulties of a mild or moderate nature [9]. The inclusion of students identified as having profound and multiple learning difficulties was the exception rather than the rule [10], [11]. Hence, mainstream teacher attitude had become a major barrier to the inclusion of these students. A study conducted in Finland [12] drew similar conclusion from a sample of 125 teachers who taught $65 \%$ of all school-age students with severe learning difficulties and profound and multiple learning difficulties and demonstrated their increased rate of physical integration of these students. Individual inclusion into full-time mainstream classrooms seldom occurred Furthermore, Avramidis and Norwich (2002) reviewed several studies and found that teachers regarded children with emotional and behavioral difficulties as the most difficult to include [9].

Concern refers to level of discomfort of individuals when interacting with people with disabilities. Inclusion of students with disabilities could be perceived as imposing additional demands on teachers and may cause a high degree of concern and anxiety among them. Graduate and pre-service teachers were not the only ones concerned with inclusive education. Experienced teachers might likewise have concerns of their own abilities to make appropriate accommodations for students or manage student needs. Previous research showed that there was a significant and negative correlation between teachers' attitudes and concerns. For example, in a study examining attitudes and concerns of 702 in-service educators in Thailand, participants who had relatively positive attitudes towards inclusive education were found had lower degree of concerns about it or vice versa [13]. Shippen, Crites, Houchins, Ramsey, and Simon (2005) determined the 
receptiveness and feelings of anxiety or calmness towards teaching students with special educational needs in an inclusive classroom setting before and after an introductory course in special education. Their sample comprised 326 graduate and pre-service teachers. The study found that both groups became more receptive to the idea of inclusion and felt calmer in terms of including students with special needs. Future general education teachers (as compared to future special education teachers) had the highest level of anxiety [14]. Forlin, Keen, and Barrett (2008) examined teacher concerns on inclusion of students with intellectual disabilities in regular settings. Teachers who had a student with intellectual disability in their class were asked to complete a questionnaire that assessed their concerns on aspects such as behavior of the student, student social competency, parental interaction, and teacher professional competency. Of the 228 respondents, 93\% stated that they felt they had received insufficient training to cater to the needs of a student with an intellectual disability in an inclusive setting. The authors concluded that the lack of pre-service teacher training for inclusive settings, as cited by the teachers, is an important consideration for training providers [15]. As the prior study focused on the lack of pre-service teacher training for inclusive settings, very few studies have focused on determining whether professional development will change in-service concerns of teachers. The current study attempts to fill that knowledge gap.

Apart from knowledge, teacher commitment to inclusion is important. Teachers need to implement effectively the strategies they learned and be fully committed to the reform [16]. Teachers need information and strategies to maintain their commitment. These key strategies to support learning for students with disabilities in a general setting include interdisciplinary instruction, team teaching, block scheduling, cooperative learning structures, creation of collaborative learning environments, effective use of support staff, providing training to parents, multiple intelligences, teaching social skills to students, varied groupings, universal design for learning, and peer teaching [9], [17]-[20]. However, few researchers have determined the influence of professional development on teacher commitment towards inclusion. This study similarly attempts to develop an item set for measuring those aspects.

Despite several studies on determining suitable psychometric tools for examining teacher perception towards professional development towards inclusion, most papers emphasized measuring teacher attitudes (e.g. the Attitudes Towards Inclusive Education Scale (ATIES) [21]) and concerns (e.g. Stages of Concern Questionnaires (SOCQ) [22]). Little has been done in investigating teacher commitment, which is believed to be an important element in professional development in inclusion. Apart from developing a construct for teacher attitudes and concerns towards professional development in inclusion, this paper attempts to add the construct of teacher commitment into the scale. No psychometric tool that can measure the teacher attitudes, concern, and commitment towards professional development in inclusion simultaneously has been created, and this paper serves to fill in those gaps.

\section{METHOD}

\section{A. Participants}

A total of 355 teachers from three progressive training courses on catering to diverse learning needs (Basic, $n=222$; Advance, $n=66$; Thematic, $n=67$ ) completed the questionnaire on teacher attitude, concern, and commitment towards inclusive education. The basic, advanced, and thematic courses were designed to enhance the professional capacity of teachers to support students with special educational needs systematically. The Education Bureau of Hong Kong has set specific training targets such that, in each ordinary primary or secondary school, at least $10 \%$ to $15 \%$ of teachers will complete the basic course, at least three to six teachers will complete the advanced course, and at least three to six teachers will complete the thematic course by the end of the 2014/15 school year. Table I presents the demographic details of the participants. Two-thirds $(70.9 \%)$ of the participants were female. Most of them $(51.7 \%)$ worked at secondary schools, followed by primary schools $(41.5 \%)$, and special schools $(6.8 \%)$. Over $95 \%$ of the teachers held a bachelor degree and/or above, and most were experienced teachers (teaching year $>5,76.2 \%$ ).

TABLE I: DEMOGRAPHIC STATISTICS

\begin{tabular}{|c|c|c|c|}
\hline & $\begin{array}{l}\text { Basic course } \\
(n=222)\end{array}$ & $\begin{array}{l}\text { Advance } \\
\text { course } \\
(n=66) \\
\end{array}$ & $\begin{array}{l}\text { Thematic } \\
\text { course } \\
(n=67)\end{array}$ \\
\hline \multicolumn{4}{|l|}{ Gender } \\
\hline Male & $68(30.6 \%)$ & $20(30.3 \%)$ & $14(20.9 \%)$ \\
\hline Female & $150(67.6 \%)$ & $46(69.7 \%)$ & $52(77.6 \%)$ \\
\hline \multicolumn{4}{|l|}{ Sector } \\
\hline Primary/Elementary school & $67(30.2 \%)$ & $32(48.5 \%)$ & $47(70.1 \%)$ \\
\hline Secondary school & $144(64.9 \%)$ & $24(36.4 \%)$ & $14(20.9 \%)$ \\
\hline Special school & $9(4.1 \%)$ & $10(15.2 \%)$ & $5(7.5 \%)$ \\
\hline \multicolumn{4}{|l|}{ Age group (year) } \\
\hline 25 and below & $15(6.8 \%)$ & - & - \\
\hline 26 to 30 & $90(40.5 \%)$ & $28(42.4 \%)$ & $30(44.8 \%)$ \\
\hline 36 to 45 & $76(34.2 \%)$ & $21(31.8 \%)$ & $23(34.3 \%)$ \\
\hline 46 and above & $40(18.0 \%)$ & $17(25.8 \%)$ & $13(19.4 \%)$ \\
\hline \multicolumn{4}{|l|}{ Academic qualification } \\
\hline Certificate & $9(4.1 \%)$ & - & $2(3.0 \%)$ \\
\hline Bachelor & $114(51.4 \%)$ & $38(57.6 \%)$ & $40(59.7 \%)$ \\
\hline Master or above & $91(41.0 \%)$ & $27(40.9 \%)$ & $22(32.8 \%)$ \\
\hline \multicolumn{4}{|l|}{ Teaching experience (year) } \\
\hline 5 and below & $57(25.7 \%)$ & $17(25.8 \%)$ & $10(14.9 \%)$ \\
\hline 6 to 10 & $45(20.3 \%)$ & $11(16.7 \%)$ & $13(19.4 \%)$ \\
\hline 11 to 20 & $76(34.2 \%)$ & $27(40.9 \%)$ & $28(41.8 \%)$ \\
\hline 21 and above & $43(19.4 \%)$ & $11(16.7 \%)$ & $15(22.4 \%)$ \\
\hline
\end{tabular}

\section{B. Measures}

For the present study, the item pool of the initial scale was created following a content analysis of six previously developed scales [4], [23]-[27]. The final review was conducted by a panel of five experts in the fields of inclusive education, assessment and evaluation, and educational psychology. The current design contains 20 items (five were distractive items) and uses a five-point Likert scale, from "strongly disagree" to "strongly agree." 


\section{Procedure}

Participants were determined and approached based on the contacts of the coordinators of the Basic, Advanced, and Thematic courses. Each participant was invited to complete the questionnaire on the course commencement date. Ethics approval was given by The Hong Kong Institute of Education, and informed consent was obtained prior to data collection.

\section{Data Analysis}

Four analyses were conducted to establish the validity and reliability of the initial scale, including exploratory factor, confirmatory factor, reliability analysis of scale internal consistency, and Rasch analysis. The details are given in the following sections.

The first analysis involves establishing unidimensionality of each scale using exploratory factor analysis. The exploratory factor analysis is used to ascertain empirically the degree to which each of the three subscales is underpinned by only one coherent dimension (e.g. attitude). Exploratory, rather than confirmatory, factor analysis is used because of the innovative nature of this study. No previous study has been undertaken in Hong Kong to analyze the in-service teachers' attitude, concern, and commitment attributes of inclusive education. Undertaking exploratory factor analysis provides more room than confirmatory factor analysis for any factor structure(s) of the items to manifest.

Exploratory factor analysis is conducted using the SPSS (Statistical Package for Social Scientists) computer software package (Version 20; SPSS, 2012). The analysis identifies the number of underlying dimensions or factors in the terminology of factor analysis for the set of items in each scale.

Several methods can be used in exploratory factor analysis to identify common tendencies from a set of Likert-type items. Literature recommends the use of the maximum likelihood method as it produces asymptotically unbiased and consistent estimates of parameters [28]. If the data have an approximate normal distribution, the maximum likelihood method 'allows for the computation of a wide range of indexes of the goodness of fit of the model and permits statistical significance testing of factor loadings [29].

The maximum likelihood method will extract all common factors and the researchers have to decide on the number of factors to retain for the final solution. Several methods can be used to determine the number of factors extracted in the exploratory factor analysis. This validation exercise utilized the SPSS default option of the Kaiser's criterion, which retained factors with eigenvalues greater than 1 .

After running the exploratory factor analysis, the factor loadings on all factors of the output are carefully inspected. Special care is given to items with factor loadings less than .3 [30], which means the items and factor do not have much commonality. Care is likewise given to any item with factor loading greater than .9 , which is referred to as a Heywood case [28], and signifies that the item dominates the meaning of the underlying factor. If all loadings are greater than .3 and there is no Heywood case, the amount of variance explained by the common factor is inspected. A factorial construct can explain a large amount of variance (around 50\%) of the items making up, and the result provides strong empirical support to items measuring the construct by design. The
Kaiser-Meyer-Olkin (KMO) measure of sampling adequacy is used to compare the magnitudes of observed correlation coefficients in relation to magnitudes of partial correlation coefficients. Large KMO values are good because correlations between pairs of variables (i.e., potential factors) can be explained by other variables. If the KMO is below .50, latent factors cannot be identified.

The second analysis involves undertaking confirmatory factor analysis. The purpose of this analysis confirms the factor structures derived from theory and the exploratory factor analysis explained above, and indicates how good the proposed (theoretical) factor model fits the data and extent to which the factors relate to one another. This analysis is conducted by using LISREL (Version 8.8) computer software packages [31], [32].

For the confirmatory factor analysis, given that the data comprise ordinal level responses from teachers based on a five-point rating scale, the estimation of a polychoric correlation matrix from the ordinal metric and the computation of an asymptotic variance-covariance matrix are necessary. The asymptotic variance-covariance matrix is then used as a weighting element in the estimation process prior to confirmatory factor analysis using LISREL [32]-[35]. These procedures were used in the current study.

Studies [36]-[39] advised that multiple measures should be used to indicate model goodness of fit. Literature has not been conclusive regarding which goodness of fit indices can be used to judge how good the model fits the data. In line with information from literature, three commonly used goodness of fit indices are reported in this validation study, namely (1) Goodness of Fit Index (GFI) [40], using the rule of thumb of a GFI value larger than .90 as indication of good fit; (2) Comparative Fit Index (CFI) [40], using a CFI value larger than .90 as indication of good fit; and (3) Root Mean Square Error of Approximation (RMSEA) [41], using a value less than .05 as an indication of good fit.

Cronbach's coefficient alpha [42], [43] is computed as a measure of reliability (internal consistency) using the SPSS computer package (Version 20; SPSS, 2012). Cronbach's coefficient alpha is a number with possible values ranging from 0 to 1 . Internal consistency refers to the interrelatedness of the items comprising the scale. The closer the coefficient is to 1 , the more reliable (internally consistent) the scale. Cronbach's coefficient alpha values greater than .7 suggest the scale is of reasonable reliability and values greater than .9 are strongly reliable. The caveat is that Cronbach's coefficient alpha values are affected by the number of items included in the scale as well as by the homogeneity of the sample. Scales with more items or varied samples will have larger Cronbach's coefficient alpha values without having more reliability.

The next step in the analysis comprised undertaking a Rasch analysis [44] on each of the scales using the WINSTEPS program [45]. The Rasch analysis aims to calibrate items on a unidimensional scale. Several statistics are informative for scale construction and calibration. Among these is the item separation index, which measures the adequacy of items comprising the scale in defining a line of increasing intensity (e.g. more positive attitudes; less concern; more eager to make commitment) in terms of the extent to which items are separated/differentiated from 
different groups/levels of persons [44]. An item separation index is similar in interpretation to traditional reliability indices. Larger Separation Index values suggest higher (Rasch) reliability than smaller Index values [46]. In literature (e.g. Smith, 2003), Separation Indices larger than 3.0 are considered adequate (can separate persons into three different clusters, i.e., high, medium, and low). The calculated point-measure correlation revealed the relationship between item and construct, which ranged from 0 to 1. According to literature (e.g. Smith, 2003), point-measure correlation larger than .3 is considered appropriate.

The Rasch analysis reported the unweighted mean square (Outfit MNSQ) statistics and weighted mean square (Infit MNSQ) statistics [46]. These measures reflected the extent to which each item fitted a Rasch Rating Scale model. Infit stands for "information-weighted fit statistic" and is "sensitive to unexpected behavior affecting responses to items near the person's ability measure," whereas outfit is affected by outliers, and identified as "outlier usual unweighted fit" [45]. Values of outfit and infit statistics that fall within the rule-of-thumb range in values between .7 and 1.3 indicate that the item fits a Rasch Rating Scale model reasonably well. However, values outside the range suggest possible misfit of items to a Rasch Rating Scale model.

A variable map and item fit statistics table were also constructed to investigate the item-person relationship. Statistically, the variable map shows the distribution of items based on the degree of difficulty of each item, which offers a schema for researchers to understand the locational relationship between item and person.

\section{RESULTS}

\section{A. Exploring Factor Structure (Dimensionality)}

Presented in Table II are the outcomes of exploratory factor analysis (EFA) from SPSS on each of the scales, using maximum likelihood method of extraction. Table II shows that three factors were identified. Factor 1 was extracted for items on the attitude scale and all item factor loadings were greater than .3 , indicating that these factors measured a coherent construct of attitude. Factor 2 was extracted for items on the attitude scale and all items had factor loadings greater than .3 for the scale. Factor 3 was extracted for items on the commitment scale, with one exception. While all items had factor loadings greater than .3 for scale, the exception was C5, "I can assist families in helping their children do well in school," which had a weak factor loading of .204 on the commitment scale. No Heywood case [28] was found in the solutions. The total variance explained by the overall factorial construct was $46.75 \%$, which met the standard of around $50 \%$. The KMO measure of sampling adequacy was .775 , which was higher than .50 , and the factor analysis can be considered as appropriate.

\section{B. Confirming Factor Structure (Construct Validity)}

Table III presents the outcomes of confirmatory factor analysis (CFA). The values show all items have factor loadings greater than .30, except for item B1, "Student with disabilities will not be accepted by the rest of the class." The GFI and CFI of the three-factor model were .986 and .941, respectively, and both were higher than .90 , indicating the model fit the data well. The RMSEA of the three-factor model was .0578, indicating reasonable, although not superb, goodness of fit. The factor-factor correlations of attitude and concern, attitude and commitment, and concern and commitment were $.408(p<.001), .450(p<.001)$, and .082 , indicating a medium correlation between attitude and concern, and attitude and commitment, but not concern and commitment. Hence, the relationship between these two factors should be further investigated. These results suggest that the three-factor model has strong construct validity for evaluating the attitude, concern, and commitment attributes of teachers in Hong Kong schools.

TABLE II: FACTOR LOADINGS FROM EXPLORATORY FACTOR ANALYSIS OF ATTITUDE, CONCERN, AND COMMITMENT SCALES

\begin{tabular}{lll}
\hline \hline & & $\begin{array}{l}\text { Factor } \\
\text { loading }\end{array}$ \\
Scale Item & \\
\hline
\end{tabular}

Attitude

A1 I dread the thought that I could eventually end .773

A2 I tend to make contacts with people with $\quad .724$ disabilities brief and I finish them as quickly as possible.

A3 I would feel terrible if I had a disability. $\quad .712$

A4 I am afraid to look directly at a person with a .684 disability.

A5 I find it difficult to overcome my initial shock .647 when meeting people with severe physical disabilities.

Concern

B1 Students with disabilities will not be accepted .763 by the rest of the class.

B2 It will be difficult to give appropriate $\quad .742$ attention to all students in an inclusive classroom.

B3 My workload will increase if I have students .702 with disabilities in my class.

B4 I will be more stressed if I have students with .539 disabilities in my class.

B5 I do not have the knowledge and skills $\quad .468$ required to teach students with disabilities.

Commitment

C1 I can provide appropriate challenges for very $\quad .825$ capable students.

C2 I can handle disruptive behavior in the $\quad .756$ classroom.

C3 I can accurately gauge student comprehension .677 of what I have taught.

C4 I can collaborate with other professionals in .311 helping students with disabilities.

C5 I can assist families in helping their children .204 do well in school.

Total variance explained $=46.75 \%(\sim 50 \%)$

Kaiser-Meyer-Olkin (KMO) measure of sampling adequacy $=.775(>.50)$

\section{Reliability (Internal Consistency)}

The reliability coefficients of attitude, concern, and commitment scales were .696, .529, and .761 (see Table IV), respectively. These coefficients are merely acceptable. For 
the concern scale, if item B1, "Student with disabilities will not be accepted by the rest of the class," is deleted, the reliability (internal consistency) would be substantially enhanced to .576. If item B5, "I do not have the knowledge and skills required to teach students with disabilities," is deleted, the reliability would be enhanced to .570 .

TABLE III: FACTOR LOADINGS FROM CONFIRMATORY FACTOR ANALYSIS OF ATTITUDE, CONCERN, AND COMMITMENT SCALES

\begin{tabular}{lll} 
& OF ATTITUDE, CONCERN, AND COMMITMENT SCALES & \\
\hline Scale & Item & $\begin{array}{l}\text { Factor } \\
\text { loading }\end{array}$ \\
\hline
\end{tabular}

Attitude

A1 I dread the thought that I could eventually end up .388** with a disability.

A2 I tend to make contacts with people with $.656^{* *}$ disabilities brief and I finish them as quickly as possible.

A3 I would feel terrible if I had a disability. $416^{* * *}$

A4 I am afraid to look directly at a person with a $.688^{* *}$ disability.

A5 I find it difficult to overcome my initial shock .729** when meeting people with severe physical disabilities.

Concern

B1 Students with disabilities will not be accepted by .166* the rest of the class.

B2 It will be difficult to give appropriate attention to .506** all students in an inclusive classroom.

B3 My workload will increase if I have students with .718** disabilities in my class.

B4 I will be more stressed if I have students with .740** disabilities in my class.

B5 I do not have the knowledge and skills required to $.234^{* *}$ teach students with disabilities.

Commitment

C1 I can provide appropriate challenges for very $.511^{* *}$ capable students.

C2 I can handle disruptive behavior in the classroom. $.593^{* *}$

C3 I can accurately gauge student comprehension of .603** what I have taught.

C4 I can collaborate with other professionals in .661** helping students with disabilities.

C5 I can assist families in helping their children do .730** well in school.

Correlation between

Attitude and Concern $=.408 * * *$

Attitude and Commitment $=.450 * * *$

Concern and Commitment $=.082$

Goodness of Fit Index $(\mathrm{GFI})=.986(>.90)$

Comparative Fit Index $(\mathrm{CFI})=.941(>.90)$

Root Mean Square Error of Approximation $($ RMSEA $)=.0578(<.08)$

$* p<.01$

$* * p<.001$

These results suggest that the scales are internally consistent for investigating teacher perception towards inclusive education in Hong Kong.

Responses to items B1 and B5 might not be entirely consistent with other items in the scale of concern, and thus, future users could consider excluding these items from the scale. However, based on the judgment made by panel members, they tend to reserve these two items to maintain a five-item construct and to ensure adequate information would be obtained through the following cohorts for further calibrations.

TABLE IV: RELIABILITY ANALYSIS OF ATTITUDE, CONCERN, AND COMMITMENT SCALES

\begin{tabular}{|c|c|c|c|c|}
\hline Scale & Item & & $\operatorname{Mean}(\mathrm{SD})$ & $\begin{array}{l}\text { Alpha if } \\
\text { item } \\
\text { deleted }\end{array}$ \\
\hline \multicolumn{5}{|c|}{ Attitude } \\
\hline & A1 & $\begin{array}{l}\text { I dread the thought that I could } \\
\text { eventually end up with a disability. }\end{array}$ & $3.48(1.34)$ & .671 \\
\hline & $\mathrm{A} 2$ & $\begin{array}{l}\text { I tend to make contacts with people } \\
\text { with disabilities brief and I finish them } \\
\text { as quickly as possible. }\end{array}$ & $4.26(1.05)$ & .629 \\
\hline & A3 & $\begin{array}{l}\text { I would feel terrible if I had a } \\
\text { disability. }\end{array}$ & $2.96(1.22)$ & .657 \\
\hline & A4 & $\begin{array}{l}\text { I am afraid to look directly at a person } \\
\text { with a disability. }\end{array}$ & $4.75(.97)$ & .653 \\
\hline & A5 & $\begin{array}{l}\text { I find it difficult to overcome my initial } \\
\text { shock when meeting people with } \\
\text { severe physical disabilities. }\end{array}$ & $4.40(1.07)$ & .624 \\
\hline
\end{tabular}

Concern

B1 Students with disabilities will not be $3.15(1.07) \quad .576$ accepted by the rest of the class.

B2 It will be difficult to give appropriate $2.39(.92) \quad .422$ attention to all students in an inclusive classroom.

B3 My workload will increase if I have $\quad 2.50(.91) \quad .389$ students with disabilities in my class.

B4 I will be more stressed if I have $2.89(.98) \quad .385$ students with disabilities in my class.

B5 I do not have the knowledge and skills $3.53(1.18) \quad .570$ required to teach students with disabilities.

Cronbach's coefficient alpha reliability $=.529$

Commitment

C1 I can provide appropriate challenges $\quad 4.23(.82)$ for very capable students.

C2 I can handle disruptive behavior in the 4.36(.81) $\quad .722$ classroom.

C3 I can accurately gauge student $\quad 4.30(.74) \quad .703$ comprehension of what I have taught.

C4 I can collaborate with other 4.64(.66) $\quad .720$ professionals in helping students with disabilities.

C5 I can assist families in helping their $4.49(.64) \quad .702$ children do well in school.

Cronbach's coefficient alpha reliability $=.761$

\section{Item Separation, Item Reliability, and Point-Measure} Correlation

Table $\mathrm{V}$ shows that item separation indices of attitude, concern, and commitment were 12.46, 6.31, and 2.90, respectively. These values indicated that the scale items separated the persons into 12,6 , and 3 different clusters among attitude, concern, and commitment dimensions. The item Rasch reliability separation indices of attitude, concern, and commitment were $.99, .98$, and .89 , respectively. These findings suggest that the scale has very high Rasch reliability. All items have point-measure correlations greater than .3.

\section{E. Item Measure/Difficulty and Item Fit Statistics}

Table V shows the ranges of item difficulties from attitude, concern, and commitment scales were -.43 to $1.39(\mathrm{SD}=.84)$, -.36 to $.65(\mathrm{SD}=.44)$, and -.25 to $.64(\mathrm{SD}=.33)$, respectively. The item fit statistics across three scales were all within the critical range, .7 to 1.3 (attitude: infit, .88 to 1.09 , outfit, .92 
to 1.11 ; concern: infit, .82 to 1.23 , outfit, .80 to 1.27 ; commitment: infit, .89 to 1.15 , outfit, .87 to 1.17$)$. These results indicate an appropriate goodness of fit along three scales.

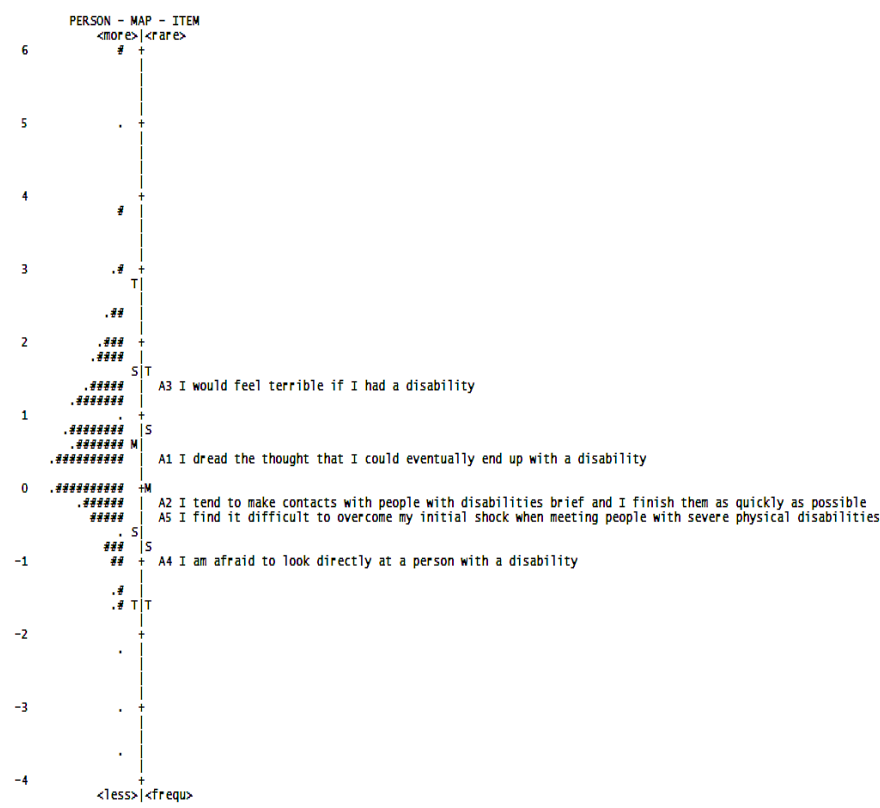

Fig. 1. Variable map of attitude scale - person (left) versus item (right) Note: \#=2; .=1.

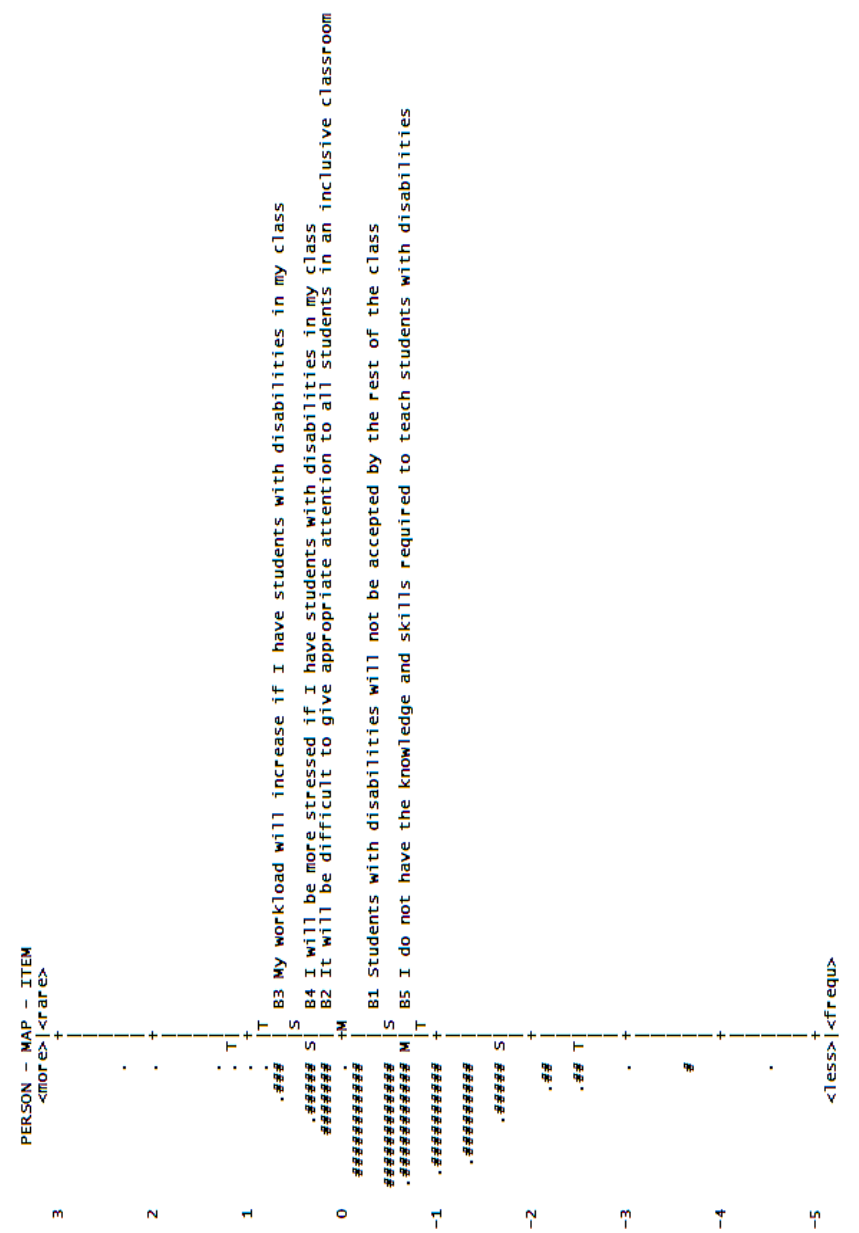

Fig. 2. Variable map of concern scale - person (left) versus item (right) Note: \#=2; .=1.

\section{F. Variable Map}

The person-item maps of attitude, concern, and commitment are presented in Fig. 1, Fig. 2, and Fig. 3. Fig. 1 shows that location of the item set was aligned with person distribution. In other words, the item distribution demonstrated an appropriate difficulty for measuring the levels of a person's ability. More specifically, only less proportions of people with extreme scores (the highest $10 \%$ and lowest $3 \%$ ) could not be adequately measured by this item set. The item set was slightly "easy" for the target population.

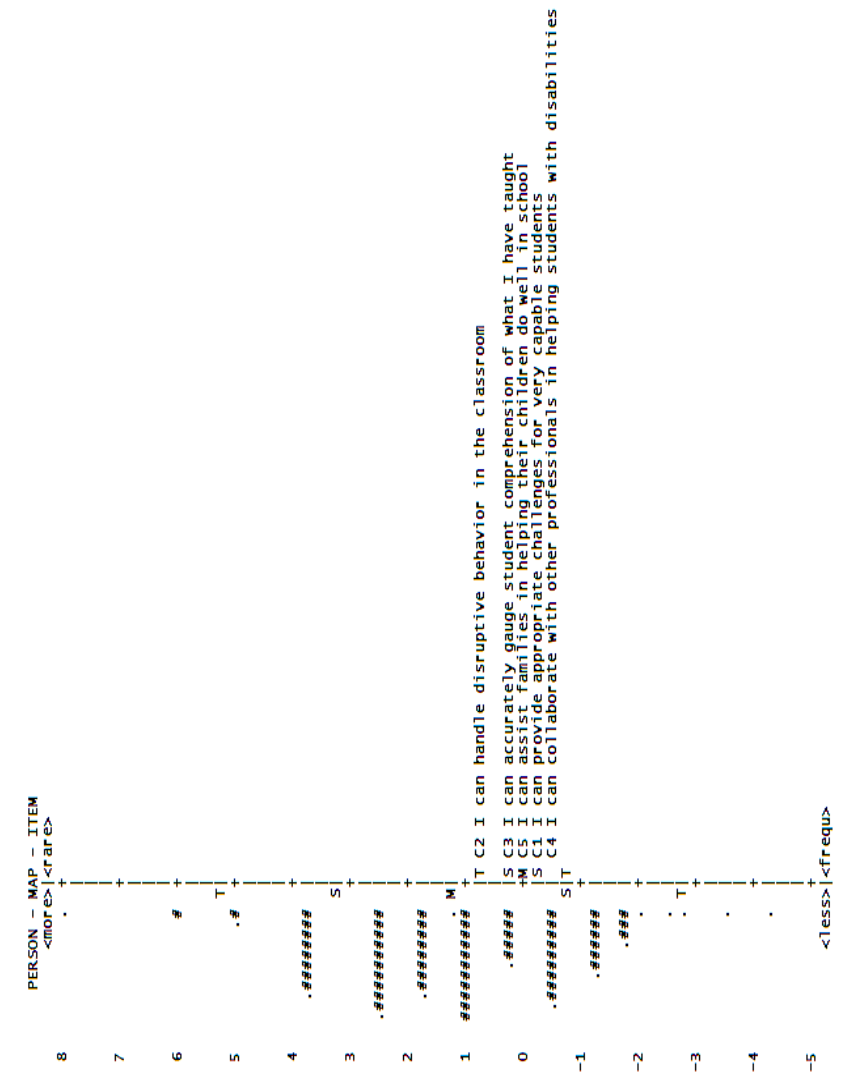

Fig. 3. Variable map of commitment scale - person (left) versus item (right) Note: \#=2; .=1.

In Fig. 2, the location of the item set was roughly aligned with person distribution. The item distribution likewise demonstrated an appropriate difficulty for measuring the levels of a person's ability. However, a certain proportion of people (the lowest 30\%) could not be adequately measured by this item set. The item set was a little "difficult" for the target population.

In Fig. 3, the items of commitment scale clustered within one standard deviation below the person mean in which the highest was $50 \%$ and the lowest was $15 \%$. Thus, people could not be measured adequately by this set of items. The item set was quite "easy" for the target population.

\section{DISCUSSION}

This study establishes the validity of a newly constructed measure on teacher attitude, concern, and commitment towards educational inclusion settings. The overall pattern of results indicates these three scales have strong construct validity, internal consistency, and good fit to the Rasch psychometric model.

\section{A. Scale Construction: EFA and CFA}

The results of factor analysis firmly identified a three-factor structure. For EFA, one item (C5), "I can assist families in helping their children do well in school," in 
commitment domain, has a low factor loading. One item (B1) in CFA, "Students with disabilities will not be accepted by the rest of the class," in concern domain had the least factor loading. However, item C5 in the CFA had the largest factor loading in commitment domain rather than the lowest loading in EFA. A similar situation can be found in item B1, which had the largest factor loading in the concern domain in EFA but had the lowest loading in CFA. After a discussion with panel members, despite a conflict on the factor loadings, these two items were kept unchanged to maintain the scale structure as whole.

\section{B. Reliability Test}

Results of the reliability test showed that if item B1, "Students with disabilities will not be accepted by the rest of the class," and item B5, "I do not have the knowledge and skills required to teach students with disabilities," were deleted, the reliability coefficient would increase. However, if these two items were deleted, only three items are left in the concern domain, and less information will yield from this domain as a result. This situation could possibly affect the overall construct of the scale. Combining attitude domain and concern domain as one is an alternative because we want to 1) investigate the relationship between concern and attitude and 2) reserve the three-factor construct explicitly. Moreover, as the preservation of items B1 and B5 is less affected than .05 on reliability coefficient, preservation was thus recommended.

\section{Rasch Analysis}

The results of item difficulty estimates revealed that generally, there are sequencing orders for each item among the three scales. Item A4, "I am afraid to look directly at a person with a disability," item B5, "I do not have the skills and knowledge required to teach students with disabilities," and item $\mathrm{C} 4$, "I can collaborate with other professionals in helping students with disabilities," were associated with the highest level (least challenge and at the bottom of the variable maps). Item A3, "I would feel terrible if I had a disability," item B3, "My workload will increase if I have students with disabilities in my class," and item C2, "I can handle disruptive behavior in the classroom," were associated with the lowest level (most challenge; at the top of the variable maps) on the scale attitude, concern, and commitment, respectively. The standard deviations of each scale can somehow be used to estimate their item separation indices. The higher the separation index, the more the differentiation cluster.

The variable map visualized all distributions between person and item to some extent and might be used to evaluate the quality of the item set in general. Among the maps, the variable map of attitude scale appears to have the highest quality. The distribution of the persons is generally aligned with the items in the concern scale. However, the items distributed at the upper part of the map just above the person mean for the commitment scale and the situation become even worse, as the item set gathered within one standard deviation in the lower middle of person distribution. These results indicated that few "easy" items might be necessary for the concern scale to differentiate the lower end's persons, whereas more "difficult" items might require the commitment scale for differentiation of the persons in the upper end.
TABLE V: RASCH ANALYSIS OF ATTITUDE, CONCERN, AND COMMITMENT SCALES

\begin{tabular}{llll}
\hline \hline & $\begin{array}{l}\text { Measure Infit } \\
\text { Scale Item }\end{array}$ & $\begin{array}{l}\text { Point-measure } \\
\text { correlation }\end{array}$ \\
\hline
\end{tabular}

Attitude

A1 I dread the thought that I $.49(.06) \quad 1.07(1.11) \quad .67$ could eventually end up with a disability.

A2 I tend to make contacts -.43(.07) .91(.92) .65 with people with disabilities brief and I finish them as quickly as possible.

A3 I would feel terrible if I $\quad 1.39(.06 \quad 1.09(1.08) \quad .66$ had a disability. )

A4 I am afraid to look directly $-.99(.07) .98(.99) \quad .60$ at a person with a disability.

A5 I find it difficult to $\quad-.45(.07) .88(.93) \quad .66$ overcome my initial shock when meeting people with severe physical disabilities.

Item separation index $=12.46$

Item reliability $=.99$

Concern

$\begin{array}{lllll}\text { B1 Students with disabilities } & -.36(.06) & 1.23(1.27) & .47\end{array}$ will not be accepted by the rest of the class.

B2 It will be difficult to give $\quad .09(.07) \quad .88(.89) \quad .63$ appropriate attention to all students in an inclusive classroom.

B3 My workload will $\quad .65(.07) \quad .82(.80) \quad .67$ increase if I have students with disabilities in my class.

B4 I will be more stressed if I .23(.07) $.82(.82) \quad .68$ have students with disabilities in my class.

B5 I do not have the $\quad-.61(.06)$ 1.23(1.25) $\quad .53$ knowledge and skills required to teach students with disabilities.

Item separation index $=6.31$

Item reliability $=.98$

Commitment

$\begin{array}{lllll}\text { C1 I can provide appropriate } & -.22(.10) & 1.15(1.17) & .68\end{array}$ challenges for very capable students.

C2 I can handle disruptive $\quad .64(.10) \quad 1.03(1.03) \quad .71$ behavior in the classroom.

C3 I can accurately gauge $\quad-.05(.10) .92(.87) \quad .72$ student comprehension of what I have taught.

C4 I can collaborate with $\quad-.25(.11) .99(1.02) \quad .69$ other professionals in helping students with disabilities.

C5 I can assist families in $\quad-.12(.12) .89(.87) \quad .73$ helping their children do well in school.

Item separation index $=2.90$

Item reliability $=.89$

\section{Reliability over CTT and IRT}

Classical test theory (CTT) and item response theory (IRT) are two different approaches adopted in this study to evaluate scale reliability. IRT-based Rasch analysis is less sensitive to 
sample variation, and might yield a higher level of reliability. Results from conventional CTT-based reliability test showed that the internal consistency (Cronbach's coefficient alpha) of the three domains were .696 (Attitude), .529 (Concern), and .761 (Commitment). A simple means of obtaining a higher level of reliability is to increase the number of items in the scale, the Spearman-Brown prophecy formula is one of the general equations used to calculate $=$ test length increment (\%) from using the CTT to IRT approach, i.e., Reliability test versus Rasch analysis. Using the Spearman-Brown prophecy formula, the test length increments for the three domains were $43.2 \%$ (Attitude), $43.6 \%$ (Concern), and $2.5 \%$ (Commitment). Thus, the test length increment demonstrates better measurement efficiency of the IRT over the CTT approach.

\section{E. Implications for Inclusive Education}

An implication arising from the present study is the provision of a valid instrument in measuring teacher attitude, concern, and commitment. As more teachers appear to access continuing professional development opportunities relevant to the education of children and young people with special educational needs, providing a sound instrument in checking the general effectiveness evaluation of teacher development or training programs is essential. This paper has great implications towards professional development in terms of inclusion, as high-quality in-service professional development opportunities should become a priority for policy makers. Indications from the present study as well as from previous related studies and reviews indicate a particular need to measure teacher attitudes, concerns, and commitment in their perceptions towards professional development in inclusion. The challenge for policy makers will be to address this issue adequately if inclusion for all pupils is to become a reality.

Similar to other scales such as The Sentiments, Attitudes, and Concerns about Inclusive Educaiton (SACIE-R) Scale for Measuring Pre-service Teachers' perceptions about inclusion [13], this scale is expected to further expand its applicability to the in-service group of teachers. However, limitations should be further explored by researchers using this instrument. All in all, there are sufficient evidence showing that this scale currently proves to provide information about changes in the levels of in-service teachers' attitudes, concerns and commitments towards inclusion.

\section{CONCLUSION}

Several methods were used to evaluate a recently constructed measure for teacher development programs on teacher perception towards inclusive settings. As a result, three subscales (attitude, concern, and commitment) were developed and tested in the Hong Kong Chinese context. The development of a current psychometric tool in this study can provide better understanding of teacher perception on educational inclusion and grant insights that can be utilized in the substantial growth of teacher training programs.

\section{REFERENCES}

[1] L. Florian and K. Black-Hawkins, "Exploring inclusive pedagogy," British Educational Research Journal, vol. 37, no. 5, pp. 813-828, 2010.
[2] A. Moran and L. Abbott, "Developing inclusive schools: the pivotal role of teaching assistants in promoting inclusion in special and mainstream schools in Northern Ireland," European Journal of Special Needs Education, vol. 17, no. 2, pp. 161-173, 2002.

[3] A. J. Wayne et al., "Experimenting with teacher professional development: motives and methods," Educational Researcher, vol. 37, no. 8, pp. 469-479, 2008

[4] E. Avramidis, P. Bayliss, and R. Burden, "A survey into Mainstream teachers' attitudes towards the inclusion of children with special educational needs in the ordinary school in one local education authority," Educational Psychology, vol. 20, no. 2, pp. 191-211, 2000.

[5] M. Fullan, The New Meaning of Educational Change, Routledge, 2013.

[6] L. C. Burrello and P. Wright, "Strategies for inclusion of behaviorally challenging students," Principal Letters: Practices for Inclusive Schools, vol. 10, 1993.

[7] T. L. Good and J. E. Brophy, Looking in Classrooms, New York: Longman, 2000.

[8] L. Terzi, "Beyond the dilemma of difference: The capability approach to disability and special educational needs," Journal of Philosophy of Education, vol. 39, no. 3, pp. 443-459, 2005.

[9] E. Avramidis and B. Norwich, "Teachers' attitudes towards integration/inclusion: A review of the literature," European Journal of Special Needs Education, vol. 17, no. 2, pp. 129-147, 2002.

[10] D. B. Male, "Who goes to SLD schools?" Journal of Applied Research in Intellectual Disabilities, vol. 9, no. 4, pp. 307-323, 1996.

[11] D. B. Male, "The impact of a professional development programme on teachers' attitudes towards inclusion," Support for Learning, vol. 26, no. 4, pp. 182-186, 2011

[12] M. Jahnukainen and A. Korhonen, "Integration of students with severe and profound intellectual disabilities into the comprehensive school system: Teachers' perceptions of the education reform in Finland," International Journal of Disability, Development and Education, vol. 50, no. 2, pp. 169-180, 2003.

[13] C. Forlin et al., "The sentiments, attitudes, and concerns about inclusive education revised (SACIE-R) scale for measuring pre-service teachers' perceptions about inclusion," Exceptionality Education International, vol. 21 , no. $2 \& 3$, pp. 50-65, 2011.

[14] M. E. Shippen et al., "Preservice teachers' perceptions of including students with disabilities," Teacher Education and Special Education: The Journal of the Teacher Education Division of the Council for Exceptional Children, vol. 28, no. 2, pp. 92-99, 2005.

[15] C. Forlin, M. Keen, and E. Barrett, "The concerns of mainstream teachers: coping with inclusivity in an Australian context," International Journal of Disability, Development and Education, vol. 55, no. 3, pp. 251-264, 2008.

[16] C. A. Grant and M. Gillette, "A candid talk to teacher educators about effectively preparing teachers who can teach everyone's children," Journal of Teacher Education, vol. 57, no. 3, pp. 292-299, 2006.

[17] E. Avramidis, P. Bayliss, and R. Burden, "Student teachers' attitudes towards the inclusion of children with special educational needs in the ordinary school," Teaching and Teacher Education, vol. 16, no. 3, pp. 277-293, 2000.

[18] M. H. Lee and C. C. Tsai, 'Exploring teachers' perceived self efficacy and technological pedagogical content knowledge with respect to educational use of the World Wide Web," Instructional Science, vol. 38 , no. 1 , pp. $1-21,2010$

[19] R. A. Stodden, L. Galloway, and N. J. Stodden, "Secondary school curricula issues: Impact on postsecondary students with disabilities," Exceptional Children, vol. 70, no. 1, pp. 9-25. 2003.

[20] J. Thousand et al., "The evolution of secondary inclusion," Remedial and Special Education, vol. 18, no. 5, pp. 270-284, 1997.

[21] F. L. Wilczenski, "Development of a scale to measure attitudes toward inclusive education," Educational and Psychological Measurement, vol. 55, no. 2, pp. 291-299, 1995.

[22] D. B. Bailey and S. A. Palsha, "Qualities of the stages of concern questionnaire and implications for educational innovations," The Journal of Educational Research, vol. 85, no. 4, pp. 226-232, 1992.

[23] M. J. Buell et al., "A survey of general and special education teachers' perceptions and inservice needs concerning inclusion," International Journal of Disability, Development and Education, vol. 46, no. 2, pp. 143-156, 1999.

[24] C. Forlin et al., "Demographic differences in changing pre-service teachers' attitudes, sentiments and concerns about inclusive education," International Journal of Inclusive Education, vol. 13, no. 2, pp. 195-209, 2009.

[25] L. Gilmore, J. Campbell, and M. Cuskelly, "Developmental expectations, personality stereotypes, and attitudes towards inclusive education: Community and teacher views of Down syndrome," 
International Journal of Disability, Development and Education, vol. 50, no. 1, pp. 65-76, 2003.

[26] U. Sharma, C. Forlin, and T. Loreman, "Impact of training on preservice teachers' attitudes and concerns about inclusive education and sentiments about persons with disabilities," Disability \& Society, vol. 23, no. 7, pp. 773-785, 2008.

[27] C. S. C. Stella, C. Forlin, and A. M. Lan, "The influence of an inclusive education course on attitude change of pre-service secondary teachers in Hong Kong," Asia-Pacific Journal of Teacher Education, vol. 35, no. 2, pp. 161-179, 2007.

[28] R. P. McDonald, Factor Analysis Related Method, Psychology Press, 1985.

[29] L. R. Fabrigar et al., "Evaluating the use of exploratory factor analysis in psychological research," Psychological Methods, vol. 4, pp. 272-299, 1999.

[30] B. G. Tabachnick, L. S. Fidell, and S. J. Osterlind, Using Multivariate Statistics, 2001.

[31] M. Du Toit, S. H. C. Du Toit, and D. M. Hawkins, Interactive LISREL: User's Guide, Scientific Software International, 2001.

[32] K. G. Jöreskog, D. Sörbom, and S. Du Toit, LISREL 8: New Statistical Features, Scientific Software International, 2001.

[33] C. DiStefano, "The impact of categorization with confirmatory factor analysis," Structural Equation Modeling: A Multidisciplinary Journal, vol. 9, no. 3, pp. 327-346, 2002.

[34] F. Holgado-Tello et al., "Polychoric versus Pearson correlations in exploratory and confirmatory factor analysis of ordinal variables,' Quality \& Quantity, vol. 44, no. 1, pp. 153-166, 2010.

[35] E. K. Kelloway, Using LISREL for Structural Equation Modeling: A Researcher's Guide, SAGE Publications, Incorporated, 1998.

[36] K. A. Bollen and J. S. Long, Testing Structural Equation Models, vol. 154, SAGE Publications, Incorporated, 1993.

[37] M. C. Hill and C. R. Tiedeman, Evaluating Model Fit, in Effective Groundwater Model Calibration, John Wiley \& Sons, Inc., pp. 93-123, 2005.

[38] H. W. Marsh, J. R. Balla, and R. P. McDonald, "Goodness-of-fit indexes in confirmatory factor analysis," Psychological Bulletin, vol. 103, no. 3, pp. 391-410, 1988.

[39] R. P. McDonald and M. M. C. Mok, "Goodness of fit in item response models," Multivariate Behavioral Research, vol. 30, no. 1, pp. 23-40, 1995.

[40] K. G. Jöreskog and D. Sörbom, LISREL VI User's Guide, Mooresville, IN: Scientific Software, 1984.

[41] J. H. Steiger and J. C. Lind, Statistically Based Tests for the Number of Common Factors, in Annual Meeting of the Psychometric Society, Iowa City, IA. 1980.
[42] L. Cronbach, "Coefficient alpha and the internal structure of tests," Psychometrika, vol. 16, no. 3, pp. 297-334, 1951.

[43] L. J. Cronbach and R. J. Shavelson, "My current thoughts on coefficient alpha and successor procedures," Educational and Psychological Measurement, vol. 64, no. 3, pp. 391-418, 2004.

[44] B. D. Wright and G. N. Masters, "Rating scale analysis," Rasch Measurement, ERIC, 1982.

[45] J. Linacre and B. Wright, WINSTEPS: Multiple-Choice, Rating Scale, and Partial Credit Rasch Analysis, [Computer software], Chicago: MESA Press, 2000.

[46] R. M. Smith, Rasch Measurement Models: Interpreting WINSTEPS/BIGSTEPS and FACETS Output, JAM Press, 2003.

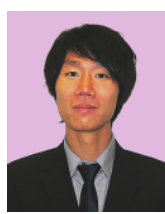

Sam Ka-Lam holds a doctor of education, master of education, and master of science degree. Dr. Sam obtained his EdD degree from the Hong Kong Institute of Education (HKIEd). He is an experienced educator and is actively conducting research from psychoeducational perspectives.

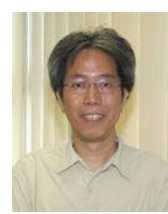

Ho Fuk-Chuen holds a doctor of philosophy degree. Dr. Ho is currently the programme co-ordinator of a professional development program for teachers. He was formerly an inspector in the Special Education Inspectorate of the Hong Kong Education Bureau. He is now the project leader of several external funded projects.

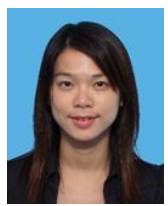

Lam Sze-Ching holds a master of social science degree in educational psychology and a master of education degree in educational guidance. She is a senior teaching fellow of the Department of Special Education and Conselling, HKIEd. She is also a registered educational psychologist in Hong Kong. 